\title{
Long-Lasting Cholinergic Modulation Underlies Rule Learning in Rats
}

\author{
Drorit Saar, ${ }^{1}$ Yoram Grossman, ${ }^{1}$ and Edi Barkai ${ }^{2}$ \\ Departments of ${ }^{1}$ Physiology and ${ }^{2}$ Morphology, Faculty of Health Sciences and Zlotowski Center for Neuroscience, \\ Ben-Gurion University of the Negev, Beer-Sheva 84105, Israel
}

\begin{abstract}
We studied the role of acetylcholine (ACh) in creating learningrelated long-lasting modifications in the rat cortex. Rats were trained to discriminate positive and negative cues in pairs of odors, until they demonstrated rule learning and entered a mode of high capability for learning of additional odors. We have previously reported that pyramidal neurons in olfactory (piriform) cortex from trained rats had reduced spike afterhyperpolarization (AHP) for $3 \mathrm{~d}$ after rule learning. In the present study we examined the mechanism underlying this long-lasting modification. The cholinergic agonist carbachol reduced both slow AHP and firing adaptation in neurons from pseudotrained rats, but had no effect on neurons from trained rats, suggesting pre-existing cholinergic effect. Intracellular application of the
\end{abstract}

calcium chelator BAPTA abolished the difference in slow AHP and in adaptation between groups, suggesting that the difference resulted from reduction in the $\mathrm{ACh}$-sensitive, $\mathrm{Ca}^{2+}$ dependent potassium current, $I_{\mathrm{AHP}}$. At the behavioral level, application of the muscarinic blocker scopolamine before each training session delayed rule learning but had no effect on further acquisition of odor memory. We suggest that intense ACh activity during rule learning enhances neuronal excitability in the piriform cortex by reducing $I_{\mathrm{AHP}}$ and that the effect outlasts the stage of rule learning, so that ACh activity is not crucial for further odor learning.

Key words: olfactory learning; piriform cortex; pyramidal neurons; neuronal adaptation; slow AHP; acetylcholine
There is a large body of evidence emanating from animal and clinical studies for cholinergic involvement in memory processes (Bartus et al., 1982; Whitehouse et al., 1982; Disterhoft et al., 1999; Weiss et al., 2000). Acetylcholine (ACh) modifies cellular responses in vivo, in auditory cortex (Metherate and Ashe, 1993), somatosensory cortex (Dykes et al., 1990), primary visual cortex (Sillito and Kemp, 1983), and piriform cortex (Linster et al., 1999). Cholinergic activity is essential for learning in a range of behavioral tasks (Sutherland et al., 1982; Hagan and Morris, 1989; Hasselmo, 1995). However, several studies have suggested a role for $\mathrm{ACh}$ in learning of a new task, but not in exercising the same task after acquisition (Aigner et al., 1991; Naor and Dudai, 1996; Orsetti et al., 1996; Miranda and Bermudez-Rattoni, 1999).

Reduced spike afterhyperpolarization (AHP) and reduced neuronal adaptation were found in rabbit hippocampal pyramidal neurons after eyeblink conditioning (Coulter et al., 1989; Moyer et al., 1996; Thompson et al., 1996) and in rat piriform cortex after odor-discrimination training (Saar et al., 1998). The calcium-dependent potassium current that underlies the slow AHP, which is reduced after learning, is blocked in hippocampal neurons by several neuromodulators and neuropeptides (Haug and Storm, 2000). In the piriform cortex it was shown to be sensitive to muscarinic-cholinergic and adrenergic modulation (Constanti and Sim, 1987). The role of cholinergic modulation in controlling the slow AHP is of particular interest, because of the direct relevance it may have on the animal's learning capabilities.

$\mathrm{ACh}$ is a likely candidate to induce learning-related long-

\footnotetext{
Received Sept. 13, 2000; revised Nov. 14, 2000; accepted Nov. 28, 2000.

This work was supported by the Israel Science Foundation.

Correspondence should be addressed to Edi Barkai, Department of Morphology, Faculty of Health Sciences, Ben-Gurion University of the Negev, Beer-Sheva 84105, Israel. E-mail: edi@bgumail.bgu.ac.il.

Copyright (C) 2001 Society for Neuroscience 0270-6474/01/211385-08\$15.00/0
}

lasting changes in neuronal excitability by reducing AHP and neuronal firing adaptation, because it suppresses frequency adaptation in vitro, in the hippocampus (Lancaster and Nicoll, 1987; Madison et al., 1987), neocortex (McCormick and Prince, 1986; Schwindt et al., 1988), and piriform cortex (Constanti and Sim, 1987; Barkai and Hasselmo, 1994). Furthermore, it was recently shown that application of a cholinergic-muscarinic agonist facilitates both neuronal excitability in CA1 hippocampal neurons and trace eyeblink conditioning (Weiss et al., 2000). However, the role of ACh in setting the observed learning-induced long-term changes in intrinsic neuronal properties and the mechanism for this modulation are yet to be described.

The rat olfactory modality offers significant advantages for the study of learning-related neuromodulation in the mammalian brain. Rats, for whom olfaction is the dominant sensory modality, can easily learn to associate odor with reward (Staubli et al., 1986; Saar et al., 1998, 1999; Sara et al., 1999). Furthermore, rats develop enhanced learning capability once they become familiar with the task (Staubli et al., 1987; Saar et al., 1998, 1999). Thus, two phases of learning occur during training: the first, rule learning phase, and the second phase in which odor memories are easily and rapidly acquired. Cholinergic modulation of odorlearning processes is apparent, because cholinergic blockers impair learning of odors (Hunter and Murray, 1989), without affecting olfactory perception or olfactory short-term memory (Wirth et al., 2000). The piriform cortex in rats receives direct, nontopographic input from the olfactory bulb, such that presentation of a single odor to a rat activates large population of cells all over this cortical region (Schoenbaum and Eichenbaum, 1995). The anatomical organization of this cortex is simple, with one defined, easily visualized layer of densely packed pyramidal cell bodies (layer II). To compare between learning groups, we aimed to record from these pyramidal cells only. We have previously 
Figure 1. Firing adaptation in layer II neurons is reduced after rule learning. $A$, Schematic description of the four-arm maze. Protocols for trained and pseudotrained rats were similar: an electronic "start" command opens randomly two of eight valves $(V)$, releasing a positive-cue odor $(P)$ into one of the arms and a negative-cue odor $(N)$ into another. Eight seconds later, the two corresponding guillotine doors $(D)$ are lifted to allow the rat to enter the selected arms. After reaching the far end of an arm (90-cm-long), the rat body interrupts an infrared beam (I, arrow), and a drop of drinking water is released from a water hose $(W)$ into a small drinking well (for a trained rat only if the arm contains the positive-cue odor, for pseudotrained rat randomly). A trial ends when the rat interrupts a beam, or in $10 \mathrm{sec}$, if no beam is interrupted. A fan is operated for $15 \mathrm{sec}$ between trials, to remove odors. $B$, Effect of scopolamine on rule learning, and on subsequent learning of additional odors. Rats injected with saline before each training session ( $n=6$ rats) reached criterion for learning the first pair of odors ( $80 \%$ positive-cue choices) after 7-10 consecutive training days. Rats injected with scopolamine $(n=6$ rats $)$ required a significantly longer period of $10-17 \mathrm{~d}$ to reach the same criterion $\left({ }^{*} p<\right.$ 0.01 ). Once rule learning is established, both groups learned the second pair of odors within $2 \mathrm{~d}$. Values represent mean \pm SE. $C$, Example for neuronal firing adaptation in layer II pyramidal cell. In response to injection of prolonged depolarizing current steps, the cell fires a single action potential at threshold current intensity $(0.65$ $\mathrm{nA})$, and train of action potentials at higher

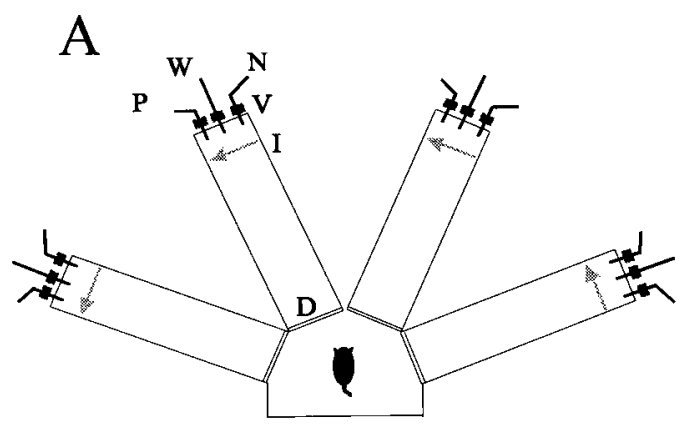

B

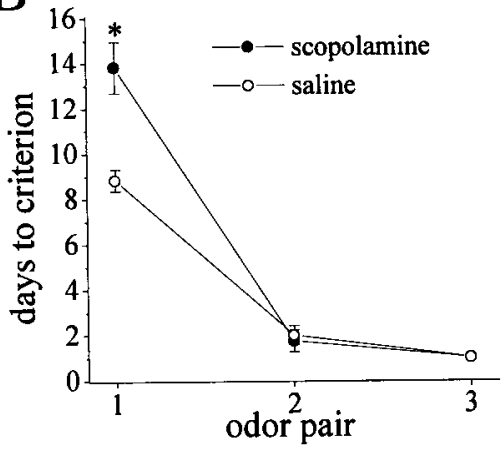

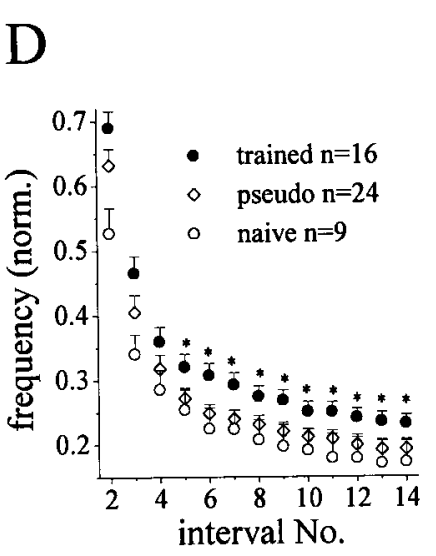

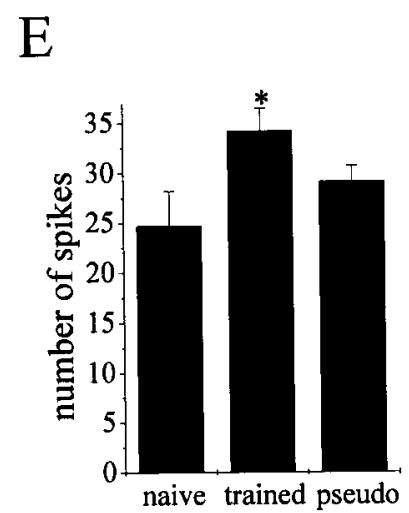
current intensities (1.05 and $1.3 \mathrm{nA}$ ), with spiking frequency that is highest at the onset of the pulse and decreases considerably thereafter. $D$, Spike firing adaptation in pyramidal neurons from the three learning groups. With stimulus intensity of $I_{\mathrm{th}} \times 2$, firing frequency at each ISI along the train was normalized to the initial frequency at the train onset. Starting from the fifth interval, the averaged normalized frequency at each ISI was significantly higher in neurons from trained rats $\left({ }^{*} p<0.05\right)$, compared with neurons from pseudotrained and naive rats, which did not differ from each other. Values represent mean \pm SE. $n=$ number of cells. Cells were recorded from 5 naive, 10 pseudotrained, and 8 trained rats. $E$, The number of spikes generated by a $1 \mathrm{sec}$ depolarizing pulse, with intensity of $I_{\text {th }} \times 2$, is significantly higher in neurons from trained rats, compared with neurons from pseudotrained and naive rats $\left({ }^{*} p<0.05\right)$.

shown that learning-related reduction in AHP in these cells appears $1 \mathrm{~d}$ after rule learning and lasts for $3 \mathrm{~d}$ (Saar et al., 1998). This long-lasting modification was shown to be correlated with rule learning, rather than with long-term consolidation of memory for the learned odors (Saar et al., 1998). In the present study we examine the role of $\mathrm{ACh}$ in setting the learning-induced changes in intrinsic neuronal properties and in enabling the two phases of learning.

\section{MATERIALS AND METHODS}

\section{Animal training}

Subjects and apparatus. Age-matched young adult Sprague Dawley male rats were used. Before training they were maintained on a $23.5 \mathrm{hr}$ water-deprivation schedule, with food available ad libitum. Olfactory discrimination training protocol was performed daily on each trained and pseudotrained rat in a four-arm radial maze (Fig. $1 A$ ), with commercial odors that are regularly used in the cosmetics and food industry.

Training. Olfactory training consisted of 20 trials per day for each rat, as described in Figure $1 A$. In short, in each trial the rat had to choose between two odors (positive- and negative-cue) presented simultaneously. Rats designated to the trained group were rewarded after choosing the positive cue. Rats in the pseudotrained group were rewarded after choosing any odor, in a random manner. The criterion for learning was at least $80 \%$ positive-cue choices in the last 10 trials of a training day, as was previously used by Staubli et al. (1986). Using the criterion of $80 \%$ positive choices throughout a training day produced the same results. Rats in the naive group were water-deprived, but not exposed to the maze. Once all the rats in the trained group met the criterion for learning the first pair of odors, on the next day both trained and pseudotrained groups resumed training with a new pair of unfamiliar odors. As we have previously reported (Saar et al., 1998, 1999), our training study confirms the original report by Staubli et al. (1987) that once the rats reach good performance with the first pair of odors, their capability to learn new odors increases dramatically (Fig. $1 B$, saline).

Drug application. The cholinergic antagonist scopolamine $(0.5 \mathrm{mg} / \mathrm{kg})$ was applied with intraperitoneal injections before each training session.

\section{Slice preparation, stimulation, and recording}

Brain slices were taken from 10 naive, 17 pseudotrained, and 14 trained rats $3 \mathrm{~d}$ after training completion, when learning-related cellular modifications were shown to be most prominent (Saar et al., 1998, 1999). Coronal brain slices of $400 \mu \mathrm{m}$ were cut as previously described (Saar et al., 1998) and kept in oxygenated $\left(95 \% \mathrm{O}_{2}+5 \% \mathrm{CO}_{2}\right)$ normal saline Ringer's solution (in mM: $\mathrm{NaCl} 124, \mathrm{KCl} 3, \mathrm{MgSO}_{4} 2, \mathrm{NaH}_{2} \mathrm{PO}_{4} 1.25$, $\mathrm{NaHCO}_{3} 26, \mathrm{CaCl}_{2} 2$, and glucose 10). Intracellular recordings were performed at $36^{\circ} \mathrm{C}$, with $4 \mathrm{~m}$ K-acetate-filled sharp glass microelectrodes. To standardize adaptation recordings, 1 sec depolarizing current steps were injected to the cell body via the recording electrode to determine the current intensity needed to generate a single action potential $\left(I_{\text {th }}\right)$, and adaptation was determined from the response to $1 \mathrm{sec}$ current step with intensity of $I_{\text {th }} \times 2$. To standardize AHP recordings, AHP amplitude was measured after a $100 \mathrm{msec}$ depolarizing current step that 
Table 1. Basic membrane properties of layer II pyramidal cells under different recording conditions

\begin{tabular}{|c|c|c|c|c|c|c|c|c|c|}
\hline & \multicolumn{3}{|l|}{ NSR } & \multicolumn{3}{|l|}{ Carbachol } & \multicolumn{3}{|l|}{ BAPTA } \\
\hline & $V_{\mathrm{m}}$ & $R_{\text {in }}$ & A.P. amp. & $V_{\mathrm{m}}$ & $R_{\text {in }}$ & A.P. amp. & $V_{\mathrm{m}}$ & $R_{\text {in }}$ & A.P. amp. \\
\hline Naive & $\begin{aligned}-84.5 & \pm 4.5 \\
n & =29(10)\end{aligned}$ & $\begin{aligned} 38.0 & \pm 9.4 \\
n & =23(10)\end{aligned}$ & $\begin{aligned} 101.3 & \pm 4.7 \\
n & =29(10)\end{aligned}$ & $\begin{aligned}-79.8 & \pm 3.4 \\
n & =7(3)\end{aligned}$ & $\begin{aligned} 43.6 & \pm 6.6 \\
n & =6(3)\end{aligned}$ & $\begin{aligned} 100.9 & \pm 4.3 \\
n & =8(3)\end{aligned}$ & $\begin{aligned}-79.9 & \pm 4.3 \\
n & =22(5)\end{aligned}$ & $\begin{aligned} 30.9 & \pm 9.1 \\
n & =17(5)\end{aligned}$ & $\begin{aligned} 103.0 & \pm 5.7 \\
n & =19(5)\end{aligned}$ \\
\hline Trained & $\begin{aligned}-82.4 & \pm 2.9 \\
n & =27(9)\end{aligned}$ & $\begin{aligned} 37.2 & \pm 9.2 \\
n & =20(9)\end{aligned}$ & $\begin{aligned} 101.1 & \pm 5.9 \\
n & =26(9)\end{aligned}$ & $\begin{aligned}-82.0 & \pm 3.9 \\
n & =18(7)\end{aligned}$ & $\begin{aligned} 37.0 & \pm 7.2 \\
n & =13(7)\end{aligned}$ & $\begin{aligned} 100.5 & \pm 6.3 \\
n & =15(7)\end{aligned}$ & $\begin{aligned}-79.4 & \pm 3.9 \\
n & =20(5)\end{aligned}$ & $\begin{aligned} 32.6 & \pm 7.4 \\
n & =19(5)\end{aligned}$ & $\begin{aligned} 101.0 & \pm 6.2 \\
n & =19(5)\end{aligned}$ \\
\hline $\begin{array}{l}\text { Pseudo- } \\
\text { trained }\end{array}$ & $\begin{aligned}-84.4 & \pm 3.8 \\
n & =39(11)\end{aligned}$ & $\begin{aligned} 37.4 & \pm 8.9 \\
n & =32(11)\end{aligned}$ & $\begin{aligned} 103.3 & \pm 4.1 \\
n & =38(11)\end{aligned}$ & $\begin{aligned}-81.2 & \pm 3.2 \\
n & =18(7)\end{aligned}$ & $\begin{aligned} 41.1 & \pm 14.5 \\
n & =15(7)\end{aligned}$ & $\begin{aligned} 102.0 & \pm 5.1 \\
n & =19(7)\end{aligned}$ & $\begin{aligned}-81.4 & \pm 3.5 \\
n & =22(4)\end{aligned}$ & $\begin{aligned} 34.4 & \pm 10.0 \\
n & =20(5)\end{aligned}$ & $\begin{aligned} 100.0 & \pm 5.2 \\
n & =21(5)\end{aligned}$ \\
\hline
\end{tabular}

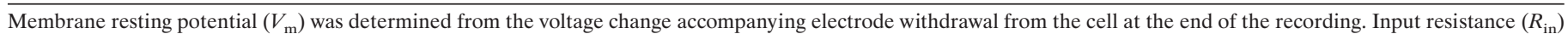

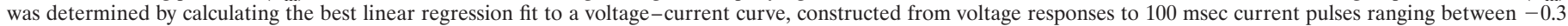

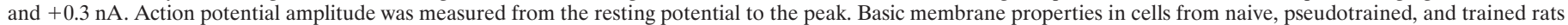

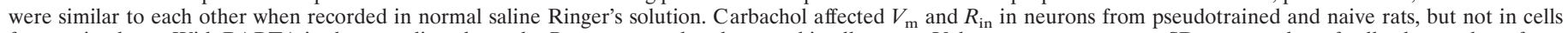

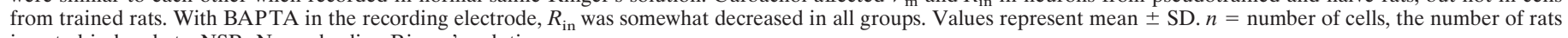
is noted in brackets. NSR, Normal saline Ringer's solution.

generates six action potentials. AHP amplitude was determined from average of eight consecutive responses to stimuli applied once every 10 sec. In these conditions a slow, cholinergic- and adrenergic-sensitive AHP appears in layer II neurons in the piriform cortex (Constanti and Sim, 1987). This AHP peaks at 30-60 msec after pulse termination (Saar et al., 1998) and lasts for up to several seconds.

The cholinergic agonist carbachol $(20 \mu \mathrm{M}$; Research Biochemicals, Natick, MA) and the cholinergic-muscarinic antagonist atropine (10 $\mu \mathrm{M}$; Sigma, St. Louis, MO) were applied via the Ringer's perfusing solution. This concentration of carbachol was previously shown to block both AHP-generating potassium currents, the $I_{\mathrm{M}}$ and the $I_{\mathrm{AHP}}$, in these neurons (Constanti and Sim, 1987).

The calcium chelator BAPTA (0.2 M; Research Biochemicals) was applied intracellularly via the recording electrode. With BAPTAcontaining electrodes, neuronal adaptation and AHP amplitude were measured at least $30 \mathrm{~min}$ after penetration, to ensure that BAPTA has diffused into the cell.

The identity of rats (naive, trained, or pseudotrained) was not known to the person conducting the experiments and measurements.

\section{Statistical analysis}

In normal saline Ringer's solution experiments, between-group comparisons of membrane properties $\left(V_{\mathrm{m}}, R_{\mathrm{in}}\right.$, spike amplitude), and betweengroup comparisons of AHP amplitudes and instantaneous firing frequencies were done using one-way ANOVA for the three learning groups, with post hoc multiple $t$ tests for each pair of groups.

In the carbachol and in the BAPTA experiments, evaluation of the treatment effect on each group was done by comparison of membrane properties with and without the treatment, using independent $t$ tests. Data from cells that were recorded in carbachol only $(n=16$ cells from pseudotrained, four cells from trained) were grouped together with data from cells that were recorded before and after carbachol wash $(n=8$ cells from pseudotrained, four cells from trained rats). Between-group comparison of basic membrane properties was done using one-way ANOVA for the three learning groups, with post hoc multiple $t$ tests for each pair of groups. Between-group comparisons of AHP amplitude and of instantaneous firing frequencies in cells from pseudotrained and trained rats was done using independent $t$ tests.

\section{RESULTS}

\section{Neuronal firing adaptation is reduced after rule learning}

We have previously shown that after odor learning, pyramidal neurons in layer II of the piriform cortex generate smaller AHP after the firing of six action potentials at holding potential of -60 $\mathrm{mV}$. Several reports have demonstrated the relation between AHP-generating currents and the ability of a cell to fire repetitively at high frequencies (Madison and Nicoll, 1984; Schwindt et al., 1988), but the mechanism underlying learning-related modifications in neuronal repetitive firing characteristics needs to be shown. Layer II pyramidal neurons respond to injection of pro- longed depolarizing current steps with firing of single action potential, at threshold current intensity $\left(I_{\text {th }}\right)$, or with a train of action potentials at higher current intensities, with spiking frequency that increases as stimulus intensity is raised (Fig. 1C). However, similar to pyramidal neurons in other brain regions, layer II cells show adaptation of the response, with firing frequency that is highest at the onset of the pulse and decreases considerably thereafter (Barkai and Hasselmo, 1994; Fig. 1C). We compared firing adaptation in neurons from trained, pseudotrained, and naive rats, $3 \mathrm{~d}$ after rule learning, when trainingrelated reduction in AHP was at its peak (Saar et al., 1998). As will be described below, AHP recordings performed in these neurons confirm our previous results, showing significant reduction in slow AHP amplitude in trained rats $3 \mathrm{~d}$ after rule learning. Cells were injected with $1 \mathrm{sec}$ depolarizing current step, with stimulus intensity of $I_{\text {th }} \times 2$, to generate a train of action potentials. As a measure of the adaptation process, interspike intervals (ISIs) along a train were measured, and the frequency at each ISI was normalized to the onset frequency. Starting from the fifth ISI, the averaged normalized firing frequency was significantly higher in neurons from trained rats, suggesting weaker adaptation process (Fig. 1D). Because no significant difference was found in basic membrane properties between groups (Table 1), this suggests learning-related reduction in adaptation-causing currents. The averaged first frequency at this stimulus intensity did not differ between the three groups $(156.4 \pm 44.0 \mathrm{~Hz}, n=16$ in neurons from trained; $164.9 \pm 54.7 \mathrm{~Hz}, n=24$ in neurons from pseudotrained; and $126.4 \pm 39.2 \mathrm{~Hz}, n=9$ in neurons from naive rats). Because the initial firing frequencies were similar, learningrelated reduced neuronal adaptation was manifested as increased number of action potentials generated during the $1 \mathrm{sec}$ pulse. The averaged number of action potentials generated in neurons from trained rats ( $34.2 \pm 9.1 \mathrm{spikes} / \mathrm{sec}, n=16)$ was significantly higher than in neurons from naive and pseudotrained rats (24.7 \pm 9.8 spikes/sec, $n=9$ and $29.1 \pm 7.4$ spikes/sec, $n=24$ respectively, $p<0.05$; Fig. $1 E$ ). Application of acetylcholine agonists to pyramidal cells in vitro reduces both AHP (Schwindt et al., 1988) and spike firing adaptation (Barkai and Hasselmo, 1994). We aimed to examine the effect of acetylcholine in layer II cells after training.

\section{ACh enhances repetitive firing in neurons from pseudotrained, but not trained rats}

Our previous studies show that after olfactory learning, the AHP amplitude does not differ between neurons from naive and from 

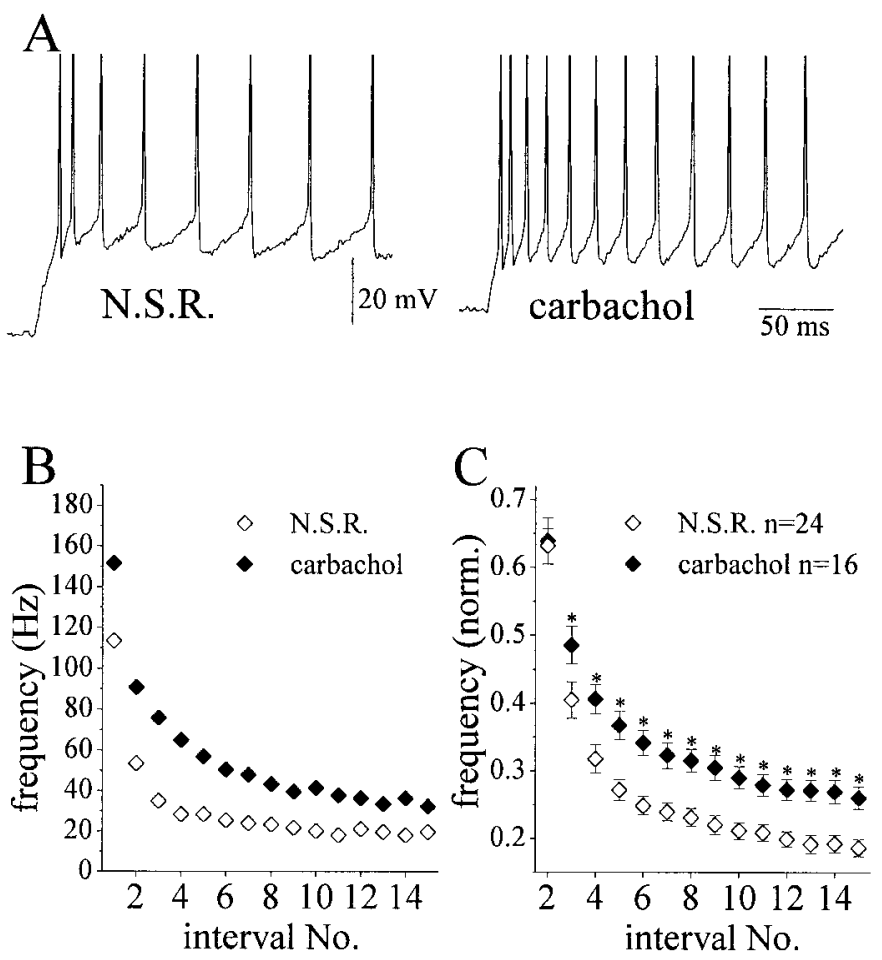

Figure 2. Carbachol reduces firing adaptation in neurons from pseudotrained rats. $A$, Example of carbachol-induced decrease in firing adaptation in a neuron from pseudotrained rat: repetitive firing in response to the same current step, before (left) and after (right) carbachol application. In carbachol, the number of spikes generated within $250 \mathrm{msec}$ from pulse onset increased from 8 to 12 . $B$, Firing frequency measured from the traces in $A$. After carbachol application, firing starts at higher frequency and decays more gradually along the train. $C$, Quantitative description of cholinergic-induced reduction in spike adaptation. With stimulus intensity of $I_{\text {th }} \times 2$, firing frequency at each ISI along the train was normalized to the initial frequency at the train onset. Starting from the third interval, the averaged normalized frequency at each ISI was significantly higher in carbachol-treated neurons $(* p<0.05)$. Values represent mean \pm SE. $n=$ number of cells. Neurons in normal saline Ringer's solution (N.S.R.) are the same as in Figure 1D, open diamonds. Some of the neurons in carbachol are the same neurons as in normal saline Ringer's solution, after carbachol wash, and some neurons were recorded in carbachol only. In total, neurons in carbachol were obtained from seven pseudotrained rats.

pseudotrained rats (Saar et al., 1998). Here we have shown that also neuronal adaptation is similar in neurons from these two control groups. Therefore, the effect of carbachol on neuronal adaptation was examined in cells from pseudotrained and trained rats only.

Application of the cholinergic agonist carbachol to the perfusing solution had a notable effect on neurons from pseudotrained rats. $I_{\text {th }}$ was significantly decreased, from $0.75 \pm 0.18 \mathrm{nA}(n=24$ cells $)$ in normal saline Ringer's solution to $0.58 \pm 0.20 \mathrm{nA}(n=17$ cells) in carbachol $(p<0.01)$. Such decrease in $I_{\text {th }}$ could result from a combination of more subtle effects observed in carbachol. As previously reported for these neurons (Barkai and Hasselmo, 1994), in carbachol membrane resting potential $\left(V_{\mathrm{m}}\right)$ was slightly but significantly $(p<0.05)$ depolarized, and input resistance $\left(R_{\text {in }}\right)$ was somewhat increased (Table 1). Application of $1 \mathrm{sec}$ current steps generated trains with firing frequency that increased after carbachol application (Fig. 2A,B). Furthermore, after carbachol application, starting from the third ISI, the averaged normalized firing frequency was significantly higher, although the intensity of the current injected $\left(I_{\mathrm{th}} \times 2\right)$ was smaller, after
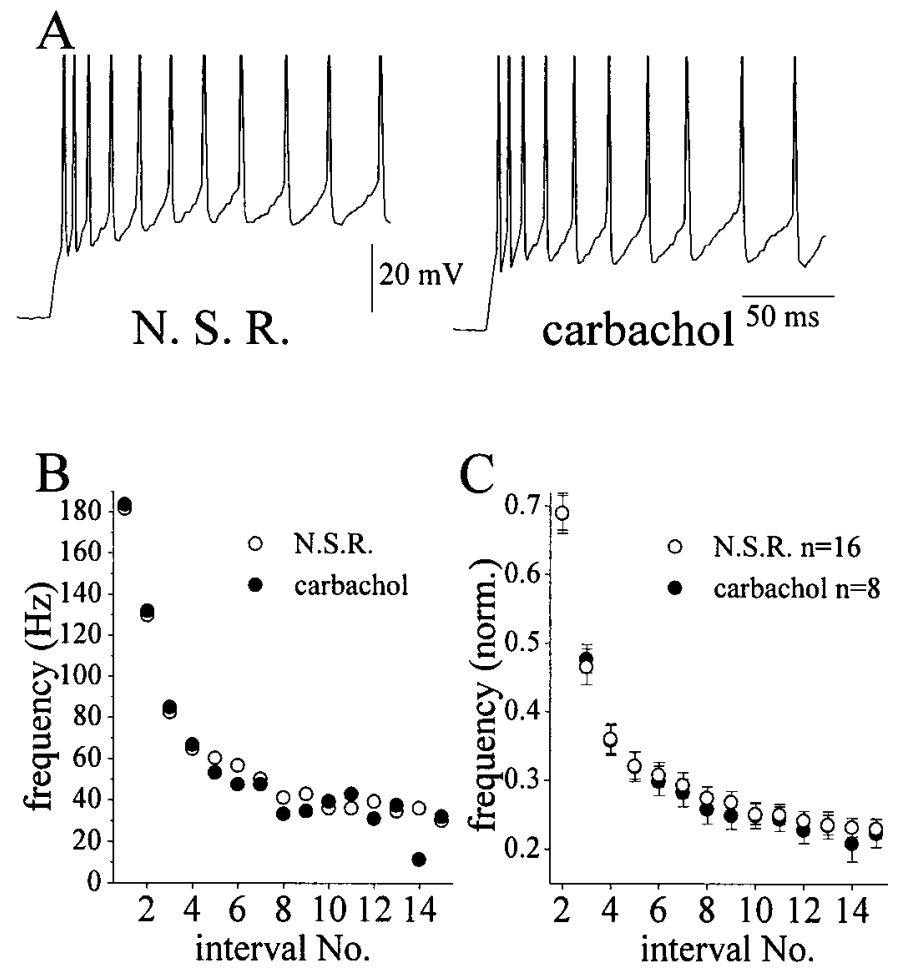

Figure 3. Carbachol has no effect on neuronal adaptation in neurons from trained rats. $A$, Neuron from a trained rat: repetitive firing in response to the same current step, before (left) and after (right) carbachol application. Firing frequency is not modified, and the number of spikes generated within $250 \mathrm{msec}$ from pulse onset is unchanged. B, Firing frequency measured from the traces in $A$. Carbachol application does not affect firing frequency in cells from trained rats. $C$, Quantitative description of firing adaptation, before and after carbachol application, in neurons from trained rats. With stimulus intensity of $I_{\mathrm{th}} \times 2$, firing frequency at each ISI was normalized to the initial frequency at the train onset. The averaged normalized firing frequency in carbachol and in normal saline Ringer's solution (N.S.R.) were similar. Values represent mean \pm SE. $n=$ number of cells. Neurons in normal saline Ringer's solution are the same as in Figure $1 D$, dark circles. Some of the neurons in carbachol are the same neurons as in normal saline Ringer's solution, after carbachol wash, and some neurons were recorded in carbachol only. In total, neurons in carbachol were obtained from five trained rats.

adjusting to the reduced $I_{\text {th }}$ (Fig. 2C). All the above effects of carbachol could be blocked by application of atropine $(n=5)$, suggesting that they were related to activation of the ACh receptors.

In sharp contrast to cholinergic effects on intrinsic neuronal properties in neurons from pseudotrained rats, carbachol had no significant effect on cells from trained rats. $R_{\text {in }}$ and $V_{\mathrm{m}}$ did not change after carbachol application (Table 1). Accordingly, $I_{\text {th }}$ remained unchanged $(0.72 \pm 0.20 \mathrm{nA}, n=17$ cells in normal saline Ringer's solution, compared with $0.77 \pm 0.24 \mathrm{nA}, n=9$ cells in carbachol). Also, neuronal adaptation was unchanged (Fig. $3 A-C$ ). Note that in carbachol, firing frequency adaptation was similar in neurons from pseudotrained and trained rats (Figs. $2 C, 3 C)$. When the number of spikes generated by standard depolarizing pulse was compared between neurons from trained and pseudotrained rats, the different effect by carbachol became even more apparent. Because carbachol application had a combined effect of significantly reducing the $I_{\mathrm{th}}$ and the firing adaptation in neurons from pseudotrained, but not from trained rats, we compared the number of action potentials generated in re- 


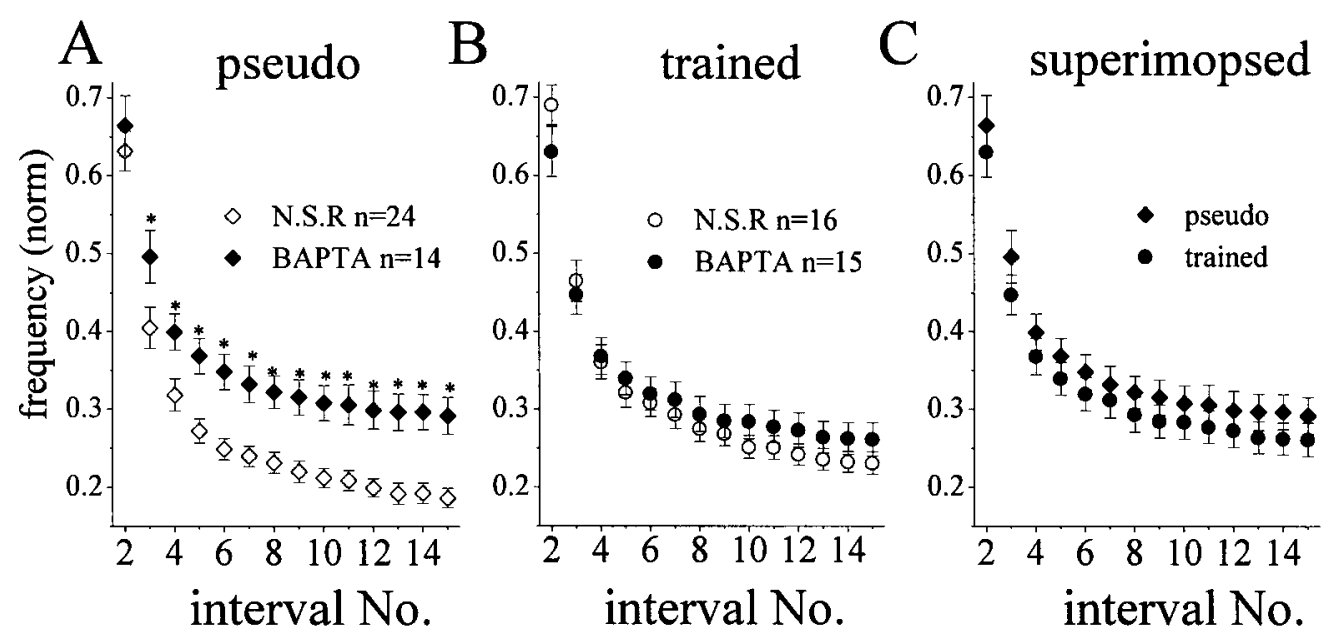

Figure 4. Differences in firing adaptation between neurons from trained and pseudotrained rats are abolished when $I_{\mathrm{AHP}}$ is blocked. Quantitative description of firing adaptation recorded with and without BAPTA in the recording electrodes. With stimulus intensity of $I_{\text {th }} \times 2$, firing frequency at each ISI was normalized to the initial frequency at the train onset. Values represent mean \pm SE. $n=$ number of cells. Neurons recorded without BAPTA are the same as in Figure $1 D$. Neurons recorded with BAPTA were obtained from six trained and four pseudotrained rats. $A$, Effect of intracellular Ca ${ }^{2+}$ chelating on firing adaptation in neurons from pseudotrained rats. Starting from the third interval, the averaged normalized firing frequency at each ISI was significantly higher when recorded with BAPTA-containing electrode $\left({ }^{*} p<0.05\right) . B$, Intracellular $\mathrm{Ca}^{2+}$ chelating does not affect firing adaptation in neurons from trained rats. There is no significant difference in the averaged normalized firing frequency in cells recorded with or without BAPTA in the recording electrode. $C$, The same cells as in $A$ and $B$ shown together, to demonstrate that with BAPTA in the recording electrodes, spike adaptation in cells from trained and pseudotrained rats is similar.

sponse to a standard $1 \mathrm{sec}$ depolarizing pulse with the intensity of $1 \mathrm{nA}$. Under these conditions, the difference between the averaged number of action potentials evoked in neurons from pseudotrained and neurons from trained rats is much less pronounced than in response to stimuli with intensity of $I_{\mathrm{th}} \times 2$. However, the averaged number of action potentials in response to such pulse increased in neurons from pseudotrained rats from $13.5 \pm 9.1$ spikes/sec in normal saline Ringer's solution $(n=24)$ to $26.5 \pm$ 12.1 spikes/sec $(n=16)$ in carbachol $(p<0.001)$. In neurons from trained rats, the number of action potentials generated was similar with or without carbachol $(15.6 \pm 11.7 \mathrm{spikes} / \mathrm{sec}, n=16$ in normal saline Ringer's solution, and $14.5 \pm 13.4$ spikes/sec, $n=8$ in carbachol).

\section{Training-induced reduction in neuronal adaptation is attributable to reduction in calcium-dependent potassium current}

The calcium-dependent potassium current $I_{\text {AHP }}$ contributes significantly to neuronal adaptation in piriform cortex pyramidal neurons and is sensitive to cholinergic modulation via muscarinic receptors (Constanti and Sim, 1987). Another calcium-dependent potassium current, $I_{\mathrm{C}}$, which affects neuronal adaptation in hippocampal neurons, was reported to be absent in piriform cortex layer II pyramidal neurons (Constanti and Sim, 1987). Also, $I_{C}$ in hippocampal neurons can affect spike width, but in our previous study (Saar et al., 1998) we did not find a change in spike width in layer II piriform neurons after olfactory training. We therefore tested whether reduced $I_{\mathrm{AHP}}$ conductance can account for the decreased adaptation in neurons from trained rats. Application of the calcium chelator BAPTA via the recording electrode caused significant reduction in neuronal adaptation in neurons from pseudotrained rats, and increased firing rate was apparent (Fig. $4 A$ ). The number of action potentials generated by a $1 \mathrm{sec}$ depolarizing pulse with stimulus intensity of $I_{\text {th }} \times 2$ was significantly higher $(38.9 \pm 8.1$ spikes, $n=14)$ in BAPTA-containing than in normal pseudotrained neurons $(29.1 \pm 7.4$ spikes, $n=24$, $p<0.05)$. In contrast, frequency adaptation in neurons from trained rats was insensitive to BAPTA application (Fig. 4B). Accordingly, the number of action potentials generated in neurons from trained rats by the same stimulus was similar in control conditions $(34.2 \pm 9.1$ spikes, $n=16)$ and in the presence of BAPTA $(33.9 \pm 8.1$ spikes, $n=15)$. With BAPTA, basic membrane properties did not differ between groups (Table 1), but the difference in frequency adaptation between pseudotrained and trained rats was abolished (Fig. 4C), indicating that the difference resulted from learning-related reduction in a $\mathrm{Ca}^{2+}$-sensitive current.

\section{Training-related reduction in AHP is attributable to ACh-induced reduction in $I_{\text {AHP }}$}

Because we have previously observed reduced AHP in neurons from trained rats, we examined whether AHP reduction was also a result of ACh-induced reduction in $I_{\mathrm{AHP}}$. The amplitude of AHP was measured from baseline to the peak of the hyperpolarizing voltage deflection that follows an evoked train of six action potentials, usually at a delay of 30-60 msec from current step termination (Fig. 5A, double-sided arrow). To determine the reversal potential of AHP, AHP was measured at different holding potentials (Fig. $5 A$, traces). Linear relationship between the membrane holding potential and AHP amplitude was apparent in all the neurons that were examined ( $R>0.95$ for all 28 plots). Averaged slope was calculated for neurons from the trained group and the neurons from the pseudotrained group, and the curves were used to compare the reversal potential and the relative conductance of the AHP between these two groups. The averaged reversal potential of AHP was similar in neurons from trained $(-77.4 \pm 2.7 \mathrm{mV}$, mean $\pm \mathrm{SD}, n=9)$ and pseudotrained $(-77.8 \pm 2.0, n=19)$ rats, whereas the averaged slope of the linear relation between AHP amplitude and $V_{\mathrm{m}}$ was significantly smaller in neurons from trained rats $(-0.30 \pm 0.03$, mean $\pm \mathrm{SD}$, $n=9)$ compared with pseudotrained $(0.37 \pm 0.07, n=19$; Fig. $5 B)$. These findings indicate that the learning-related reduction in 

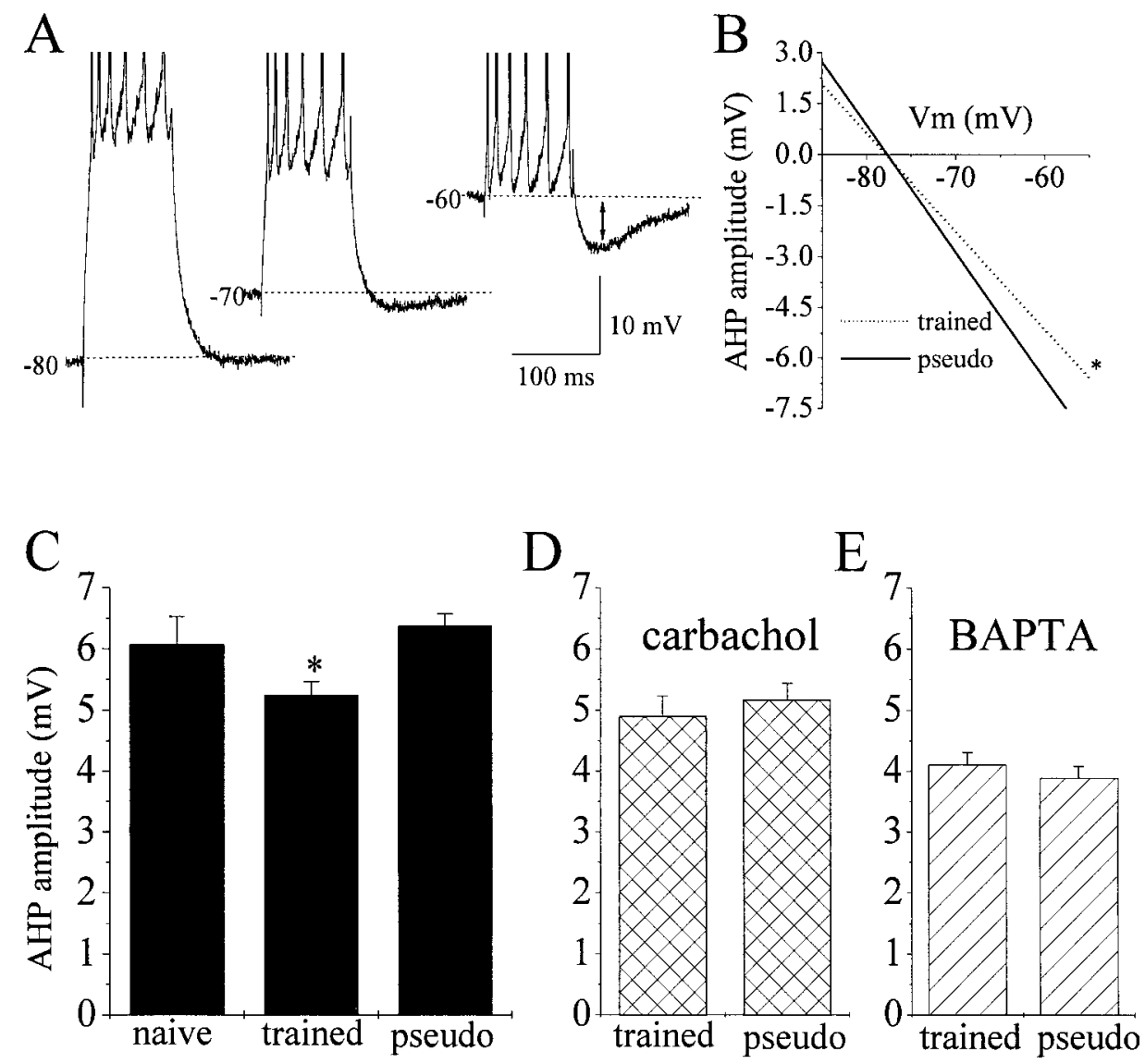

Figure 5. The difference in AHP between neurons from trained and pseudotrained rats results from ACh-induced reduction in a Ca ${ }^{2+}$-sensitive conductance. AHP was generated by $100 \mathrm{msec}$ depolarizing current step injection via the recording electrode, with intensity sufficient to generate a train of six action potentials. $A$, Examples for AHP, recorded at different membrane potentials. Membrane was held at different potentials by direct current injection. Note that AHP amplitude becomes more pronounced at more depolarized membrane holding potentials. $B$, Learning-induced reduction in apparent AHP conductance. AHP amplitude was measured at several membrane potentials between -75 and $-55 \mathrm{mV}$, and a best linear curve fit was calculated. The lines represent the averaged slope of these lines in each group. The averaged slope in trained rats was significantly smaller than in pseudotrained rats $\left({ }^{*} p<0.01\right)$. The averaged AHP reversal potential, determined from extrapolation of each line to the $x$-axis, was similar between groups. $C$, Averaged AHP amplitude at $V_{\mathrm{m}}=-60 \mathrm{mV}$ (see double-sided arrow in $A$ ). Averaged AHP amplitude in trained rats is significantly smaller compared with naive and pseudotrained rats $(* p<0.05$ ). AHP was measured in 14 neurons from six naive rats, 20 neurons from eight trained rats, and 32 neurons from 11 pseudotrained rats. Values represent mean \pm SE. $D$, Averaged AHP amplitude at $V_{\mathrm{m}}=-60 \mathrm{mV}$, in carbachol-containing solution. The difference in AHP amplitude between trained and pseudotrained rats is abolished. AHP amplitude in pseudotrained rats was divided by a factor of 1.09 , to compensate for the carbachol-induced increase in $R_{\text {in }} \cdot n=16$ neurons from seven pseudotrained rats, eight neurons from five trained rats. Values represent mean \pm SE. $E$, Averaged AHP amplitude at $V_{\mathrm{m}}=-60 \mathrm{mV}$, recorded with BAPTA-containing electrodes. The difference in AHP amplitude between trained and pseudotrained rats is abolished. $n=19$ neurons from five pseudotrained rats, 20 neurons from five trained rats. Values represent mean \pm SE.

AHP is not attributable to modifications in the ionic composition of the currents underlying it, but rather in the apparent conductance of the AHP currents. That the reversal potential of the AHP deviates from the expected reversal potential of a pure potassium conductance, indicates that other, more depolarizing conductances (such as a chloride conductance) are also present, when the AHP-generating conductance is activated.

To examine the role of $\mathrm{ACh}$ in modifying the apparent conductance of AHP, the amplitude of AHP was measured under standard conditions (after a train of six action potentials, at holding potential of $-60 \mathrm{mV}$ ) in normal saline Ringer's solution and in carbachol. In normal saline Ringer's solution, The averaged AHP amplitude was significantly smaller in neurons from trained rats compared with neurons from pseudotrained rats (Fig. $5 C$ ), confirming our pervious report (Saar et al., 1998). Note that the averaged reduction in AHP amplitude $(-18.5 \%)$ was similar to the averaged reduction in the slope of AHP versus $V_{\mathrm{m}}$ $(-20.2 \%)$. In carbachol, the averaged AHP amplitude was signif- icantly reduced in neurons from pseudotrained rats and only slightly reduced in neurons from trained rats, so that the difference between groups was abolished (Fig. 5D).

When recorded with BAPTA-containing electrodes under the same standard conditions, AHP amplitude was significantly smaller in both trained and pseudotrained rats, but here too, the difference in averaged AHP amplitude between groups was abolished (Fig. 5E).

\section{Block of cholinergic activity delays rule learning but has no effect on subsequent memory acquisition}

The finding that cholinergic activity can affect piriform cortex pyramidal neurons in rats before rule learning, but has no effect on these neurons in rats which have completed that stage, brings up the hypothesis that intense cholinergic activity during rule learning induces long-term modifications, which outlast the rule learning stage, and enable the subsequent fast learning of additional odors. This hypothesis raises the prediction, that blocking 
the muscarinic-mediated cholinergic modulation should have an effect on rule learning, but not on subsequent memory acquisition. To examine this prediction, rats were injected with the muscarinic blocker scopolamine $(0.5 \mathrm{mg} / \mathrm{kg})$ before every training session. Rats injected with scopolamine learned the first pair of odors significantly slower $(13.8 \pm 2.7 \mathrm{~d})$ compared with rats injected with similar volumes of saline $(8.8 \pm 1.17 \mathrm{~d}, p<0.01)$. However, once the first pair of odors was learned, further scopolamine injections had no effect on the rate of subsequent learning, and criterion for learning the second pair of odors was reached within $2 \mathrm{~d}$ in both groups (Fig. $1 B$ ), similar to the learning rate reported previously for untreated rats (Saar et al., 1998, 1999). Lack of scopolamine effect on memory acquisition, once rule learning was established, is well correlated with the lack of cholinergic effect on firing frequency and on AHP in neurons from trained rats after rule learning.

\section{DISCUSSION}

\section{Role of $\mathrm{ACh}$ in olfactory learning}

In agreement with several studies that have demonstrated a role for ACh in learning of a new task, but not in subsequent exercising of the same task (Aigner et al., 1991; Naor and Dudai, 1996; Orsetti et al., 1996; Miranda and Bermudez-Rattoni, 1999), our data show that whereas cholinergic modulation is essential for rule learning in odor-discrimination task, it has no effect on subsequent fast learning of additional odors. A parallel reduction is observed in cholinergic potency to affect intrinsic neuronal properties: carbachol significantly reduces AHP and firing adaptation in pseudotrained rats, but it has no effect on these parameters after rule learning has been established. Thus, behavioral and cellular data suggest that ACh has a role in the first learning stage, by setting the proper dynamics for rule learning. In this stage, the piriform cortex neuronal circuit enters a "learning mode" that is characterized by enhanced neuronal excitability as well as enhanced synaptic transmission (Saar et al., 1998, 1999). However, once such "learning mode" is evident, ACh has no further role in additional odor-memory acquisition.

\section{The mechanism underlying reduction in AHP amplitude and neuronal adaptation}

Reduced neuronal adaptation is evident in neurons from trained rats. With prolonged depolarizing current steps, the difference in firing frequency becomes significant starting from the fifth interspike interval, suggesting that it results from a current that develops with a slow onset. Indeed, the slow AHP that develops in these neurons after a train of action potentials, which reflects such adaptation-causing currents, is reduced after learning. It was previously suggested that AHP reduction in hippocampal CA1 neurons after classical conditioning results from modification in calcium-activated potassium currents (Sanchez-Andres and Alkon, 1991). Such muscarine-sensitive calcium-activated potassium current, the $I_{\mathrm{AHP}}$, dominates neuronal adaptation and AHP amplitude in piriform cortex pyramidal neurons (Constanti and Sim, 1987). Several observations suggest that reduction in this current underlies the enhanced excitability observed after odor learning: AHP in neurons from trained and pseudotrained rats have the same reversal potential, indicating that learning-related reduction in AHP does not result from a new current that masks the hyperpolarizing effect of $I_{\mathrm{AHP}}$. Indeed, the AHP apparent conductance is reduced to a similar extent as its amplitude. Blocking the rise in intracellular calcium concentration with BAPTA, reduced the AHP amplitude and the adaptation in neurons from pseudotrained rats more than in cells from trained rats, so that the difference between the two groups was abolished. This suggests that the difference between groups results from reduction in a $\mathrm{Ca}^{2+}$-dependent current, and because $I_{\mathrm{C}}$ is absent in layer II pyramidal cells in the piriform cortex (Constanti and Sim, 1987), the most probable candidate is the $I_{\mathrm{AHP}}$.

\section{Long-lasting cholinergic effects}

We have previously shown that AHP in layer II pyramidal cells is reduced for $3 \mathrm{~d}$ after rule learning (Saar et al., 1998). Here we show that carbachol application reduces AHP, $I_{\text {th }}$, and firing adaptation in neurons from pseudotrained rats, but not from trained rats. The combined cholinergic effects on reducing $I_{\mathrm{th}}$ and neuronal adaptation in neurons from pseudotrained rats creates a state in which the number of spikes generated within $1 \mathrm{sec}$ in response to the same stimulus intensity increases by almost twice in these neurons, whereas the number of spikes in neurons from trained rats is not modified by carbachol application. Furthermore, in carbachol, AHP amplitude and firing adaptation in pseudotrained rats were similar to those in trained rats. These data indicate that the learning-related long-lasting modifications in neuronal excitability are induced by cholinergic activity. Longterm activation of second messenger systems, such as the protein kinase C and calcium-calmodulin kinase (Malenka et al., 1986; Agopyan and Agopyan, 1991; Muller et al., 1992; Pineda et al., 1995) may account for such long-lasting effects. Furthermore, in trained rats carbachol loses its ability to affect other membrane properties that are not mediated by block of the $I_{\mathrm{AHP}}$, such as $R_{\mathrm{in}}$, $V_{\mathrm{m}}$, and $I_{\text {th. }}$, which are modulated by acetylcholine via block of the potassium-mediated leak current (Madison et al., 1987; Benson et al., 1988) or activation of a nonspecific cation-mediated current (Fraser and MacVicar, 1996; Klink and Alonso, 1997). This implies a more general reduction in cholinergic capability to modify postsynaptic currents. Possible mechanisms for such general effect are reduced sensitivity, or downregulation of postsynaptic cholinergic receptors. Indeed, based on immunocytochemical studies, it was suggested that several learning paradigms result with enhanced internalization of muscarinic receptors in hippocampal and neocortical pyramidal neurons (Van der Zee and Luiten, 1999).

In conclusion, our data suggest a role for ACh in blocking the $\mathrm{Ca}^{2+}$-sensitive potassium current in piriform cortex pyramidal cells during odor-discrimination learning, thus enabling enhanced responses, with higher firing frequency. The effect of ACh outlasts the stage of rule learning, suggesting activation of intracellular signal transduction events, and excluding the need for ACh activity during the subsequent stage of fast odor learning.

\section{REFERENCES}

Agopyan N, Agopyan I (1991) Effects of protein kinase C activators and inhibitors on membrane properties, synaptic responses, and cholinergic actions in CA1 subfield of rat hippocampus in situ and in vitro. Synapse 7:193-206.

Aigner TG, Walker DL, Mishkin M (1991) Comparison of the effects of scopolamine administrated before and after acquisition in a test of visual recognition memory in monkeys. Behav Neurol Biol 55:61-67.

Barkai E, Hasselmo ME (1994) Modulation of the input/output function of rat piriform cortex pyramidal cells. J Neurophysiol 72:644-658.

Bartus RT, Dean RL, Beer B, Lippa AS (1982) The cholinergic hypothesis of geriatric memory dysfunction. Science 217:408-416.

Benson DM, Blitzer RD, Landau EM (1988) An analysis of the depolarization produced in guinea-pig hippocampus by cholinergic receptor stimulation. J Physiol (Lond) 404:479-496.

Constanti A, Sim JA (1987) Calcium-dependent potassium conductance in guinea-pig olfactory cortex neurons in vitro. J Physiol (Lond) 387:173-194.

Coulter DA, Lo Turco JJ, Kubota M, Disterhoft JF, Moore JW, Alkon 
DL (1989) Classical conditioning reduces amplitude and duration of calcium-dependent afterhyperpolarization in rabbit hippocampal pyramidal cells. J Neurophysiol 61:971-981.

Disterhoft JF, Kronfrost-Collins M, Oh MM, Power JM, Preston AR, Weiss C (1999) Cholinergic facilitation of trace eyeblink conditioning in aging rabbits. Life Sci 64:541-548.

Dusek JA, Eichenbaum H (1997) The hippocampus and memory for orderly stimulus relations. Proc Natl Acad Sci USA 94:7109-7114.

Dykes R, Metherate R, Tremblay N (1990) Transient and prolonged effects of acetylcholine on responsiveness of cat somatosensory cortical neurons. J Neurophysiol 63:223.

Fraser DD, MacVicar BA (1996) Cholinergic-dependent plateau potential in hippocampal CA1 pyramidal neurons. J Neurosci 16:4113-4128.

Hagan JJ, Morris RGM (1989) The cholinergic hypothesis of memory: a review of animal experiments. In: Psychopharmacology of the aging nervous system (Iversen LL, Snyder SH, eds), pp 237-324. New York: Plenum.

Hasselmo ME (1995) Neuromodulation and cortical function: modeling the physiological basis of behavior. Behav Brain Res 65:1-27.

Haug T, Storm JF (2000) Protein kinase A mediates the modulation of the slow $\mathrm{Ca}^{2+}$-dependent $\mathrm{K}^{+}$current, $\mathrm{I}_{\mathrm{sAHP}}$, by the neuropeptides CRF, VIP, and CGRP in hippocampal pyramidal neurons. J Neurophysiol 83:2071-2079.

Hunter AJ, Murray TK (1989) Cholinergic mechanisms in a simple test of olfactory learning in the rat. Psychopharmacology (Berl) 99:270-275.

Klink R, Alonso A (1997) Ionic mechanisms of muscarinic depolarization in enthorhinal cortex layer II neurons. J Neurophysiol 77:1829-1843.

Lancaster B, Nicoll RA (1987) Properties of two calcium-activated hyperpolarizations in rat hippocampal neurons. J Physiol (Lond) 389:187-203

Linster C, Wyble BP, Hasselmo ME (1999) Electrical stimulation of the horizontal limb of the diagonal band of broca modulates population EPSPs in piriform cortex. J Neurophysiol 81:2737-2742.

Madison DV, Nicoll RA (1984) Control of the repetitive discharge of CA1 pyramidal neurons in vitro. J Physiol (Lond) 354:319-331.

Madison DV, Lancaster B, Nicoll RA (1987) Voltage clamp analysis of cholinergic action in the hippocampus. J Neurosci 7:733-741.

Malenka RC, Madison DV, Andrade R, Nicoll RA (1986) Phorbol esters mimic some cholinergic actions in hippocampal pyramidal neurons. J Neurosci 6:475-480.

McCormick DA, Prince DA (1986) Mechanisms of action of acetylcholine in the guinea-pig cerebral cortex in-vitro. J Physiol (Lond) 375:169-194

Metherate R, Ashe JH (1993) Ionic flux contributions to neocortical slow waves and nucleus basalis-mediated activation: whole-cell recordings in vivo. J Neurosci 13:5312-5323.

Miranda MI, Bermudez-Rattoni F (1999) Reversible inactivation of the nucleus basalis magnocellularis induces disruption of cortical acetylcholine release and acquisition, but not retrieval of aversive memories. Proc Natl Acad Sci USA 96:6478-6482.

Moyer JR, Thompson LT, Disterhoft JF (1996) Trace eyeblink conditioning increases CA1 excitability in a transient and learning specific manner. J Neurosci 16:5536-5546.

Muller W, Petrozzino JJ, Griffith LC, Danho W, Connor JA (1992) Specific involvement of $\mathrm{Ca}\left({ }^{2+}\right)$-calmodulin kinase II in cholinergic modulation of neuronal responsiveness. J Neurophysiol 68:2264-2269.
Naor C, Dudai Y (1996) Transient impairment of cholinergic function in the rat insular cortex disrupts the encoding of taste in conditioned taste aversion. Behav Brain Res 79:61-67.

Orsetti M, Casamenti F, Pepeu G (1996) Enhanced acetylcholine release in the hippocampus and cortex during acquisition of an operant behavior. Brain Res 724:89-96.

Pineda JC, Bargas J, Flores-Hernandez J, Galarraga E (1995) Muscarinic receptors modulate the afterhyperpolarizing potential in neostriatal neurons. Eur J Pharmacol 281:271-277.

Saar D, Grossman Y, Barkai E (1998) Reduced after-hyperpolarization in rat piriform cortex pyramidal neurons is associated with increased learning capability during operand-conditioning. Eur J Neurosci $10: 1518-1523$

Saar D, Grossman Y, Barkai E (1999) Reduced synaptic facilitation between pyramidal neurons in the piriform cortex after odor-learning. J Neurosci 19:8616-8622.

Sanchez-Andres JV, Alkon DL (1991) Voltage-clamp analysis of the effects of classical conditioning on the hippocampus. J Neurophysiol 65:796-807.

Sara SJ, Roullet P, Przybyslawski J (1999) Consolidation of memory for odor-reward association: beta-adrenergic receptor involvement in the late phase. Learn Mem 6:88-96.

Schoenbaum G, Eichenbaum H (1995) Information coding in the rodent prefrontal cortex. 1. Single-neuron activity in orbito-frontal cortex compared with that in pyriform cortex. J Neurophysiol 74:733-750.

Schwindt PC, Spain WJ, Foehring RC, Chubb MC, Crill WE (1988) Slow conductances in neurons from cat sensorimotor cortex in-vitro and their role in slow excitability changes. J Neurophysiol 59:450-467.

Sillito AM, Kemp JA (1983) Cholinergic modulation of the functional organization of the cat visual cortex. Brain Res 289:143-55.

Staubli U, Fraser D, Kessler M, Lynch G (1986) Studies on retrograde and anterograde amnesia of olfactory memory after denervation of the hippocampus by enthorinal cortex lesions. Behav and Neural Biol 46:432-444.

Staubli U, Fraser D, Farady R, Lynch G (1987) Olfaction and the "data" memory system in rats. Behav Neurosci 101:757-765.

Sutherland RJ, Wishaw IO, Regher J (1982) Cholinergic receptor blockade impairs spatial localization by use of distal cues in the rat. J Comp Physiol Psychol 96:563-573.

Thompson LT, Moyer JR, Disterhoft JF (1996) Transient changes in excitability of rabbit CA3 neurons with a time course appropriate to support memory consolidation. J Neurophysiol 76:1836-1849.

Van Der Zee and Luiten PGM (1999) Muscarinic acetylcholine receptors in the hippocampus, neocortex, and amygdala: a review of immunocytochemical localization in relation to learning and memory. Prog Neurobiol 58:409-471.

Weiss C, Preston AR, Oh MM, Schwarz RD, Welty D, Disterhoft JF (2000) The M1 muscarinic agonist CI-1017 facilitates trace eyeblink conditioning in aging rabbits and increases the excitability of CA1 pyramidal neurons. J Neurosci 20:783-790.

Whitehouse PJ, Price DL, Struble RG, Clark AW, Coyle JT, Delon MR (1982) Alzheimer's disease and senile dementia: loss of neurons in the basal forebrain. Science 215:1237-1239.

Wirth S, Lehmann O, Bertrand F, Lazarus C, Jeltsch H, Cassel JC (2000) Preserved olfactory short-term memory after combined cholinergic and serotonergic lesions using $192 \mathrm{IgG}$-saporin and 5,7-dihydroxytryptamine in rats. NeuroReport 11:347-350. 